\title{
Information asymmetry, time until deal completion and post-M\&A performance
}

\author{
Ephraim Kwashie Thompson and Changki Kim \\ Business School, Korea University-Anam Campus, \\ Seongbuk-gu, Republic of Korea
}

Post-M\&A

performance

Received 12 June 2020 Revised 7 July 2020 Accepted 16 July 2020

\begin{abstract}
This paper aims to show that information asymmetry plays a vital role in the post-M\&A performance-time until deal completion nexus. The findings are that the due diligence hypothesis and the overdue hypothesis proposed and tested in Thompson and Kim (2020) are influenced by the information asymmetry of the target during the negotiation process. Thus, mergers that involve more opaque targets that take a shorter time to close perform better, whereas those that take too long to close experience poor post-M\&A performance. Conversely, there is no such effect when the mergers involve targets that are transparent and not plagued with large information asymmetry problems. These results hold for the short-term supporting the evidence that information asymmetry problems are severe before the merger is consummated and become attenuated post-merger.
\end{abstract}

Keywords Information asymmetry, M\&A performance, Due diligence hypothesis, Overdue hypothesis, Time until deal completion

Paper type Research paper

\section{Introduction}

The merger and acquisition (M\&A) market is an obscure market that is characterized by closed-door negotiations between acquirers and targets. Thompson and Kim (2020) argued that the time it takes until deals close is a very vital source of information to investors in such a market. Caiazza and Pozzolo (2016) indicate that the time it takes for a deal to successfully close or get abandoned can provide information on the ex-ante probability that it will succeed or fail. Investors among other factors, read vital signals from the time it takes until deal completion, update their beliefs about the ex-ante probability of success or failure based on this information and then reward or punish acquirers based on this information (Luypaert and Caneghem, 2014). Further, if the signals about the ex-ante probability of success or failure of the acquirer post-merger as read by the market and reflected in stock performance are correct, then not only stock performance but also the actual performance of the acquirer in terms of financial performance should also be affected. We posit that, if the

(C) Ephraim Kwashie Thompson and Changki Kim. Published in Journal of Derivatives and Quantitative Studies: 선물연구. Published by Emerald Publishing Limited. This article is published under the Creative Commons Attribution (CC BY 4.0) licence. Anyone may reproduce, distribute, translate and create derivative works of this article (for both commercial and non-commercial purposes), subject to full attribution to the original publication and authors. The full terms of this licence may be seen at http://creativecommons.org/licences/by/4.0/legalcode

\section{JEL classification - G34, G14}

This research was funded by the Ministry of Education of the Republic of Korea and the National Research Foundation of Korea (NRF-2016S1A5A2A03927597). The authors express their gratitude to the editor and are grateful to the anonymous reviewers for their comments in improving this article.

(1)

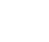


JDQS 28,3

ex-ante prediction of post-merger performance by the market based on the time until deal completion is reflected through actual financial performance, it will be a more robust justification of the informational content and implication of time until the deal completions for merger deals. Thus, if the time until deal completion's effect on stock performance is reflected in actual performance, then it suggests that the effect is not just an irrational reaction of the market but rather, the time until deal completion is an informational source of what can be expected as the outcome of a deal post-merger.

In Thompson and Kim (2020), the authors proposed two hypotheses - the due diligence hypothesis and the overdue hypothesis - to explain the implication of time until deal completion for post-merger performance and failure. They found increasing returns to acquirers who close deals within an optimum time while beyond an optimal deal closing time, the acquirer suffers low post-merger profitability indicating the presence of a non-monotonic inverse U-shaped relationship between post-merger performance and time until deal completion. Despite their interesting findings, there is no theoretical model to make sense of the phenomenon they document. In this paper, we present a simple theoretical model that explains the due diligence hypothesis and overdue hypothesis, as well as the role information asymmetry plays in this effect. We also attempt an empirical test of this model and present evidence in support of the model, thus confirming the due diligence hypothesis and overdue hypothesis.

We show that the opaqueness of targets drives the post-M\&A performance-time until deal completion nexus. The information and assertions made by targets are easily verifiable and trustworthy when there are no or little information asymmetry concerns and decisionmaking is quick. However, for targets that are besetted with large information asymmetry problems, there is a need for acquirers to spend time and incur costs to obtain and verify information about them (Bartov and Bodnar, 1996; Kesner et al., 1994; Cramton, 1991). The informational disadvantage faced by acquirers, exacerbated by the existence of initial public offering markets have been studied in the literature (Spence, 1974; Reuer and Shen, 2004; Goktan, 2013). Thus, ceteris paribus, deals involving targets, which are opaque (high information asymmetry) should be associated with a stronger effect of the due diligence hypothesis and the overdue hypothesis effect, while we expect little or no such effect for deals that involve transparent targets (low information asymmetry).

In addition, from the foregoing, we also posit that the inverse U-shaped relationship between the post-merger performance of the acquirer and the time until deal completion should be temporary for transparent targets, while they should take longer to dissipate for opaque targets. After the merger, the acquirer will gain easy access to information about the target, and therefore, this effects should become attenuated over time (Howe and Morillon, 2017). Our results confirm all these projections.

This paper contributes to the present literature in a number of ways. First, we update the findings in Thompson and Kim (2020), where the due diligence hypothesis and the overdue hypothesis effect is first proposed and the evidence documented. In this present paper, we attempt to identify one of the driving forces behind this effect. We show the impact of information asymmetry as being critical in the post-M\&A performance-time until deal completion nexus both theoretically and empirically.

Second, this paper contributes to the continuous debate on the optimum time required for closing M\&A deals. Demidova (2014) investigates whether longer negotiation time is productive or wasteful and its influence on the probability of deal completion. While Demidova focuses on the impact of deal negotiation time on deal completion success or failure, we focus on the impact of time until completion on the performance of the newly merged firm postmerger and study the impact of target information asymmetry. 
We structure the rest of the papers as follows. We present our theoretical model in Section 2 and discuss the data collection process and other relevant methodologies used for this study in Section 3. We present the results and discuss them in Section 4 while we conclude the paper in Section 5.

\section{Theoretical model}

We begin this section by first briefly summarizing the due diligence hypothesis and the overdue hypothesis documented in Thompson and Kim (2020). According to the due diligence hypothesis, if acquirers spend time undertaking adequate transactional due diligence, there is increasing post-merger performance to the acquirer because such due diligence enables the acquirer to verify that no "material adverse event" hazardous to the value of the target firm has occurred (Wangerin, 2019); ensure that detailed provisions critical to deal success are not overlooked and targets do not conceal earnings management (Easterwood, 1998); and allow for target and bidder uncertainty to be resolved before the deal is closed (Fuller, 2003). On the other hand, the overdue hypothesis posits that beyond an optimal deal closing time, acquirers suffer low post-merger profitability because of loss of timeliness and expected deal synergies engendered by changes in target fundamentals (Bhagwat et al., 2016); rising expenditures and opportunity costs from delays (Hwang and Roh, 2015; Luypaert and De Maeseneire, 2015; Ferreira et al., 2017); and losses arising from loss of focus on daily operations due to prolonged negotiations (Picquet, 2017). These two hypotheses suggest the presence of a non-monotonic inverse $U$-shaped relationship between post-merger performance and time until deal completion. We now present a simple model to explain the two hypotheses above. In our model, the investor is not privy to the closed-door negotiations between the acquirer and the target; the main source of information to the investor after the announcement of a deal is the time it takes until deal completion. We define the following variables of interest.

- $\quad t$ : announcement time of deal, $t_{o}$ : optimum deal closing time, $t_{c}$ : actual deal closing time.

- $I_{x, t}$ : information set of acquirer about itself by the announcement date of merger, $t$.

- $I_{y, t}$ : information set of target about acquirer by the announcement date of merger, $t$.

- $I_{a, t}$ : information set of acquirer about target by the announcement date of merger, $t$.

- $I_{b, t}$ : information set of target about itself by the announcement date of merger, $t$.

- $I_{m, t}:$ information set of investor about acquirer by the announcement date of merger, $t$.

- $I_{x, t}$ : information set of investor about the target by the announcement date of merger, $t$.

- $\quad P_{i}$ : firm value, where the subscript $i=x, y, a, b, n$ or $m$, depending on which player estimates it and whether in reference to the acquirer or target.

- $g_{i}$ : future cash flows, where the subscript $i=x, y, a, b, n$ or $m$, depending on which player estimates it and whether in reference to the acquirer or target.

- $f_{i}$ : discounted future cash flows from $g_{i}$, where subscript $i=x, y, a, b, n$ or $m$.

- $r$. discount rate.

- $\quad k$ : benefits of synergy from the merger of acquirer and target.

- $s$ : loss of benefits of synergy due to delay.

- $c$ : costs from undertaking due diligence by acquirer about target information as estimated by acquirer. 
- $c_{n}$ : costs from undertaking due diligence by acquirer about target information as estimated by investor.

- $z$ : benefits to the acquirer from undertaking due diligence as estimated by acquirer.

- $z_{n}$ : benefits to the acquirer from undertaking due diligence as estimated by investor.

There are three players in the market; acquirer, target and investor who are all assumed to be rational and possess different information sets.

By announcement date, $t$, the acquirer's valuation about its own future value based on its information set $I_{x, t}$ at time, $t$, is:

$$
P_{x, t}=E\left(r g_{x, t} \mid I_{x, t}\right)=E\left(f_{x, t} \mid I_{x, t}\right), \text { where } f_{x, t} \mid I_{x, t} \sim N\left(\mu_{x}, \sigma_{x}^{2}\right)
$$

whereas its valuation about the future value of the target based on information set, $I_{a, t}$, is:

$$
P_{a, t}=E\left(r g_{a, t} \mid I_{a, t}\right)=E\left(f_{a, t} \mid I_{a, t}\right), \text { where } f_{a, t} \mid I_{a, t} \sim N\left(\mu_{a}, \sigma_{a}^{2}\right)
$$

Similarly, the target makes valuations about its future value based on information set, $I_{b, t}$, as:

$$
P_{b, t}=E\left(r g_{b, t} \mid I_{b, t}\right)=E\left(f_{b, t} \mid I_{b, t}\right) \quad \text { where } f_{b, t} \mid I_{b, t} \sim N\left(\mu_{b}, \sigma_{b}^{2}\right)
$$

and values the acquirer's future value based on information set, $I_{y, t}$, as:

$$
P_{y, t}=E\left(r g_{y, t} \mid I_{y, t}\right)=E\left(f_{y, t} \mid I_{y, t}\right), \quad \text { where } f_{y, t} \mid I_{y, t} \sim N\left(\mu_{y}, \sigma_{y}{ }^{2}\right)
$$

The investor also forms his opinion about the future value of the acquirer and the target when he receives the news about the merger. Based on his information set, $I_{m, t}$, he values the acquirer as:

$$
P_{m, t}=E\left(r g_{m, t} \mid I_{m, t}\right)=E\left(f_{m, t} \mid I_{m, t}\right) \quad \text { where } f_{m, t} \mid I_{m, t} \sim N\left(\mu_{m}, \sigma_{m}^{2}\right)
$$

whereas he values the target's future value using the information set, $I_{n, t}$, as:

$$
P_{n, t}=E\left(r g_{n, t} \mid I_{n, t}\right)=E\left(f_{n, t} \mid I_{n, t}\right), \quad \text { where } f_{n, t} \mid I_{n, t} \sim N\left(\mu_{n}, \sigma_{n}^{2}\right)
$$

If it is assumed that the merger will result in synergic benefits of $k$, then the acquirer's evaluation of the future value of the proposed newly merged firm at time, $t$, is:

$$
\begin{aligned}
P_{x, t}+P_{a, t} & =E\left(r g_{x, t} \mid I_{x, t}\right)+E\left(r g_{a, t} \mid I_{a, t}\right)+E(\mathrm{k})=E\left(f_{x, t} \mid I_{x, t}\right)+E\left(f_{a, t} \mid I_{a, t}\right)+E(\mathrm{k}) \\
& =E\left(f_{x, t}+f_{a, t}+k \mid I_{x, t} I_{a, t}\right)
\end{aligned}
$$

and the target firm's valuation of the proposed newly merged firm at time, $t$, is:

$$
\begin{aligned}
P_{y, t}+P_{b, t} & =E\left(r g_{y, t} \mid I_{y, t}\right)+E\left(r g_{b, t} \mid I_{b, t}\right)+E(\mathrm{k})=E\left(f_{y, t} \mid I_{y, t}\right)+E\left(f_{b, t} \mid I_{b, t}\right)+E(\mathrm{k}) \\
& =E\left(f_{y, t}+f_{b, t}+k \mid I_{y, t} I_{b, t}\right)
\end{aligned}
$$

The investor values the proposed newly merged firms at time, $t$, as:

$$
\begin{aligned}
P_{m, t}+P_{n, t} & =E\left(r g_{m, t} \mid I_{m, t}\right)+E\left(r g_{n, t} \mid I_{n, t}\right)+E(\mathrm{k})=E\left(f_{m, t} \mid I_{m, t}\right)+E\left(f_{n, t} \mid I_{n, t}\right)+E(\mathrm{k}) \\
& =E\left(f_{m, t}+f_{n, t}+k \mid I_{m, t} I_{n, t}\right)
\end{aligned}
$$


In an efficient market, the stock price reaction will depend upon investors' expectations of future value. The acquirer's stock price will drop if the market considers the M\&A to be a value-destroying decision and vice versa (Luypaert and Caneghem, 2014). Thus, in the discussion that follows, we examine the changes to equation (9) under various scenarios:

- The case of no information asymmetry.

All market players have access to the same information set without any frictions and without incurring any further costs (Lambert et al., 2012). The costs incurred by the acquirer to obtain and validate information about the target for the purpose of making a decision is zero or negligible $(\mathrm{c} \cong 0)$. Further, delays and its attendant loss of synergies are non-existent or negligible $(s \cong 0)$. Mathematically, under no information asymmetry, the information set possessed by acquirers, targets and investors about the acquirer firm is expressed as $I_{x, t}=$ $I_{y, t}=I_{m, t}$ and the information set the three players possess about the target firm is $I_{a, t}=I_{b, t}=$ $I_{n, t}$. This convergence of beliefs by the three players in the market means the valuation of the three players with respect to the future value of the proposed newly merged firm should be the same (Armstrong et al., 2011) as follows:

$$
E\left(f_{x, t}+f_{a, t}+k \mid I_{x, t} I_{a, t}\right)=E\left(f_{y, t}+f_{b, t}+k \mid I_{y, t} I_{b, t}\right)=E\left(f_{m, t}+f_{n, t}+k \mid I_{m, t} I_{n, t}\right)
$$

- The case of information asymmetry related to the target.

Under information asymmetry problems related to the target, the information set possessed by acquirers, targets and investors about the acquirer firm remains $I_{x, t}=I_{y, t}=I_{m, t}$ and the information set the three players possess about the target firm is $I_{b, t}>\left(I_{a, t}=I_{n, t}\right)$. The target has the ability to take advantage of a misinformed or inadequately informed acquirer (Akerlof, 1970; Hansen, 1987). Therefore, the acquirer has to obtain and validate information concerning the target (Bartov and Bodnar, 1996; Kesner et al., 1994; Cramton, 1991) to make an informed decision during negotiation to prevent opportunistic behavior of the target (Louis and Sun, 2016). We consider two cases below:

Case 1: When the acquirer closes the deal but before or at the optimum time, $\left(t_{c} \leq t_{o}\right)$, then $c>0$ and $z>0$. As the acquirer is assumed to be rational, it will incur the cost, $c$, only if it brings greater benefits of $z$ over $c$, and thus, $z>c$ (Coase, 1937; Williamson, 1975). There are no delays so $s \cong 0$. As the investor is rational and also knows the acquirer is rational, the investor takes the time until deal completion as a valid signal about the quality of the deal and so, as the acquirer closes the deal and does so on time, the investors raises his valuation of the target by $z_{n}-c_{n}>0$ (Therefore, $p_{n, t_{c}}>p_{n, t}$ ). In fact, the precise value of $p_{n, t_{c}} \mid I_{n, t_{c}}$ as estimated by the investor is $E\left(f_{n, t}+z_{n}-c_{n} \mid I_{n, t}\right)[1]$. Thus, the investor values the proposed newly merged firms at time, $t_{c}$, as:

$$
P_{m, t}+P_{n, t_{c}}=E\left(f_{m, t} \mid I_{m, t}\right)+E\left(f_{n, t_{c}} \mid I_{n, t_{c}}\right)+E(\mathrm{k})=E\left(f_{m, t}+k+f_{n, t}+z_{n}-c_{n} \mid I_{m, t} I_{n, t}\right)
$$

and the difference between the investor's valuation at $t_{c}$ and his initial valuation at $t$ is:

$$
\begin{aligned}
{\left[P_{m, t}+P_{n, t_{c}}\right]-\left[P_{m, t}+P_{n, t}\right]=} & {\left[E\left(f_{m, t} \mid I_{m, t}\right)+E\left(f_{n, t_{c}} \mid I_{n, t_{c}}\right)+E(\mathrm{k})\right] } \\
& -\left[E\left(f_{m, t} \mid I_{m, t}\right)+E\left(f_{n, t} \mid I_{n, t}\right)+E(\mathrm{k})\right] \\
= & E\left(f_{n, t_{c}}-f_{n, t} \mid I_{n, t} I_{n, t_{c}}\right)=E\left(f_{n, t}+z_{n}-c_{n}-f_{n, t} \mid I_{n, t}\right) \\
= & E\left(z_{n}-c_{n}\right)>0
\end{aligned}
$$


The difference between the new value and the initial value being greater than zero implies increasing abnormal returns to the acquirer/newly merged firm post-merger.

Case 2: When the acquirer closes the deal after the optimum time, $\left(t_{c}>t_{o}\right)$, then $\mathrm{c}>0$ and $z>0$. As the acquirer is assumed to be rational, it will incur the cost, $c$, only if it brings benefits of $z$ greater than $c$, and thus, $z>c$. There is a delay beyond the optimum closing time so $s>0$. The investor takes the time until deal completion as a valid signal about the quality of the deal. As the acquirer closes the deal eventually, the investors raises his valuation of the target by $z_{n}-c_{n}>0$ but of lower magnitude than Case one above as it takes a longer time (Hwang and Roh, 2015). In addition, the negative effect from the delay in terms of the loss of synergies and opportunities come into effect so $s>0$ (Luypaert and De Maeseneire, 2015). Thus, the investor values the proposed newly merged firms at time, $t_{c}$, as:

$$
\begin{aligned}
P_{m, t}+P_{n, t_{c}} & =E\left(f_{m, t} \mid I_{m, t}\right)+E\left(f_{n, t_{c}} \mid I_{n, t_{c}}\right)+E(\mathrm{k})-E(\mathrm{~s}) \\
& =E\left(f_{m, t}+k-s+f_{n, t}+z_{n}-c_{n} \mid I_{m, t} I_{n, t}\right)
\end{aligned}
$$

and the difference between the investor's valuation at $t_{c}$ and his initial valuation at $t$ is:

$$
\begin{aligned}
{\left[P_{m, t}+P_{n, t_{c}}\right]-\left[P_{m, t}+P_{n, t}\right]=} & {\left[E\left(f_{m, t} \mid I_{m, t}\right)+E\left(f_{n, t_{c}} \mid I_{n, t_{c}}\right)+E(\mathrm{k})-E(\mathrm{~s})\right] } \\
& -\left[E\left(f_{m, t} \mid I_{m, t}\right)+E\left(f_{n, t} \mid I_{n, t}\right)+E(\mathrm{k})\right] \\
= & E\left(f_{n, t_{c}}-f_{n, t}-s \mid I_{n, t} I_{n, t_{c}}\right) \\
= & E\left(f_{n, t}+z_{n}-c_{n}-f_{n, t}-s \mid I_{n, t}\right)=E\left(z_{n}-c_{n}-s\right)<0
\end{aligned}
$$

From equation (14) above, if the acquirer closes the deal after the optimum closing time, the investor still assumes the acquirer to be rational and so even though the decision is delayed [2], closing the deal itself is a positive signal. However, the delay causes loss of synergies making the initial valuation to be decreased implying decreasing abnormal returns to the acquirer/newly merged firm post-merger.

Cases 1 and 2 above form the basis of the due diligence hypothesis and the overdue hypothesis, respectively. The increasing abnormal returns to the acquirer/newly merged firm post-merger and the subsequent decreasing abnormal returns suggests the existence of an optimal deal closing time.

A very important role is played by information asymmetry in our discussions above. If the model is valid, then we should observe the due diligence hypothesis and overdue hypothesis effect more strongly for firms that are opaque than for firms that are transparent. This leads us to $H 1$ as follows:

H1. The due diligence hypothesis-overdue hypothesis effect is severe when target have more information asymmetry problems (opacity) while it does not hold or has little impact when targets are not plagued by such problems, ceteris paribus.

Finally, after the acquirer closes the deal and is merged with the target, it is now easier to access information concerning the target. If the due diligence hypothesis-overdue hypothesis effect is mainly driven by information asymmetry targets as projected in our model, then we can expect this effect to dissipate over time after the merger is consummated because of the 
acquirer's increased access to information (Howe and Morillon, 2017). This leads us to H2 as below:

H2. The observed phenomenon of the due diligence hypothesis and the overdue hypothesis effect is temporary and stronger in the short term, ceteris paribus.

It is important to note that, we do not aim at showing evidence of causality. Our focus is to document further evidence that ex-ante, the time it takes until deal completion can give hint about post-merger performance and that this effect is driven by target information asymmetry.

\section{Data and methodology}

Our sample is from the Thomson Reuters Securities Data Company Platinum Mergers and Acquisitions database. We collect local public US M\&A from 1990 to 2015 that are completed and are disclosed value deals. We collect data on stock returns from the Center for Research in Security Prices and collect firm fundamentals from COMPUSTAT.

As argued from the model earlier, Cases one and two above form the basis of the due diligence hypothesis and the overdue hypothesis where increasing abnormal returns to the acquirer/newly merged firm post-merger and subsequent decreasing abnormal returns suggests the existence of an optimal deal closing time and a non-monotonic inverse U-shaped relationship between subsequent performance and time until deal completion. We, therefore, perform a combined test of the two hypotheses by regressing our performance measure on the time until deal completion and its squared term and also conduct a test of inverse U-shaped relationship to confirm the existence of this non-monotonic relationship. For $H 1$, to test the impact of information asymmetry as being a driving force behind the observed post-merger performance-time until deal completion nexus, we partition the sample into deals involving high information asymmetry targets (opaque targets) and low information asymmetry targets (transparent targets). Finally, for tests of $H 2$, we run our tests for different time intervals to ascertain how long the impact of the due diligence hypothesis and the overdue hypothesis effect lasts.

We used the following controls: cash dummy, difference in industry dummy, ownership percentage, Tobin's $\mathrm{Q}$ of the acquirer, size of the acquirer, the cash flow of the acquirer, leverage of the acquirer, gross domestic product (GDP) growth and total stock market development growth. Refer to Appendix for a detailed description of these variables.

For stock performance, we adopt the cumulative abnormal return or the buy-and-hold abnormal return depending on the horizon. For financial performance, we use the change in return on assets. For testing the existence of an inverse U-shaped relationship between subsequent performance and time until deal completion, we use the Lind and Mehlum (2010) test. We correct for heteroscedasticity in all our models by using robust standard errors and deal with autocorrelation among firms by clustering at the firm level.

In addition, we delete observations where the announcement date is the same as the completion date because there is no lapse between the announcement date and the completion date.

There are a number of variables that have been used in the literature to measure and proxy for information asymmetry or opacity of a firm. Prime among them include accounting information-based measures such as the accruals quality, intangible assets scaled by sales, Tobin's Q and firm size (log of total assets); market-based measures such as bid-ask spread (the difference between bid prices and ask prices); and analystbased measures such as analyst coverage (the number of analyst following), standard deviation of analyst forecasts and analyst forecast error. In this paper, we mainly use 
JDQS 28,3

the target's accruals quality as developed by Dechow and Dichev (2002) and applied by Francis et al. (2005) and Kim and Qi (2010) to proxy for information asymmetry. Accruals quality measure the extent to which total current accruals map into operating cash flow realizations and has been posited in the literature as a better measure of information asymmetry. As financial statements are the primary information source to learn about firm performance, accruals quality measures the clarity of the information contained in the financial reports of firms (Lee and Masulis, 2009). Lee and Masulis argue that the other typical proxies for asymmetric information (Tobin's Q, size, stock return volatility, components of the bid-ask spread and analyst forecast dispersion) may have multiple interpretations. Because of the tendency for multiple interpretations of other information asymmetry proxies to cloud out the interpretations of our findings, we adopt the accrual quality of the target as the main proxy for information asymmetry in this study. $\mathrm{Yu}$ (2012) also indicate the advantages of using accruals quality over other forms of measures used for information asymmetry. First, accruals quality is not influenced by stock market microstructure and trading activity. Second, it is a more focused and clear measure of information disparity compared to firm characteristics such as firm size. Third, analyst-based measures only cover a section of large firms, and thus, tend to exclude a large fraction of firms. In addition, accruals quality encompasses both the intentional misstatements and unintentional errors resulting from management lapses and environmental uncertainty (Francis et al., 2005).

We follow Francis et al. (2005) and Core et al. (2008) and divide accrual quality into quintile groups. The first two quintiles are used as the low information asymmetry group while the last two quintiles are used as the high information asymmetry group. We also use the firm size and the Tobin's Q of targets as alternate proxies for information asymmetry for robustness checks. We divide the firm size variable of the target into three groups (terciles) and use the first tercile as the high information asymmetry group (opaque targets) and the third tercile as the low information asymmetry group (transparent targets). We follow a similar process for Tobin's Q of the target firm using the first tercile as the low information asymmetry group (transparent targets) and the third tercile as the high information asymmetry group (opaque targets).

\section{Empirical results}

\subsection{Main results}

We begin this section by presenting the descriptive statistics of the variables used in this study in Table 1. Table 1 shows that the mean time until deal completion is about six and half months. This figure is higher than the mean of two months reported in Thompson and Kim (2020) and a number of reasons could account for this observations. Thompson and Kim (2020) used a cross border sample from 2000 to 2010 while we only use local US firms from 1990 to 2015 as our sample. This observation is not out of order as Boeh (2011) find evidence that cross-border M\&As are more quickly executed. We divide the sample into high information asymmetry firms and low information asymmetry firms. We observe that it takes about eight months for deals to be completed in the low information asymmetry group while it takes about six months to be completed in the high information asymmetry group, which does not align with what we would normally expect. This observation hindsight could be pointing to us that less due diligence may have been undertaken in deals involving high information asymmetry targets or conversely that the deals involving low information asymmetry targets may have been unduly delayed. Apart from the time until deal completion, the differences between the transparent targets and the opaque targets are 


\begin{tabular}{|c|c|c|c|c|c|c|c|c|}
\hline \multirow[b]{2}{*}{ Variables } & \multicolumn{4}{|c|}{ Whole sample } & \multirow{2}{*}{$\begin{array}{c}\text { Transparent targets } \\
\text { Mean }\end{array}$} & \multirow{2}{*}{$\begin{array}{c}\text { Opaque targets } \\
\text { Mean }\end{array}$} & \multirow{2}{*}{$\begin{array}{c}P \text {-value } \\
\text { (difference) }\end{array}$} & \multirow{2}{*}{$\begin{array}{l}\text { Post-M\&A } \\
\text { performance }\end{array}$} \\
\hline & Mean & $\mathrm{SD}$ & Min & Max & & & & \\
\hline Time until completion & 6.51 & 11.15 & 0.03 & 175.67 & 7.86 & 5.80 & $0.00 * * *$ & \\
\hline Cash payment & 0.65 & 0.48 & 0.00 & 1.00 & 0.60 & 0.58 & 0.40 & \\
\hline Industry difference & 0.12 & 0.32 & 0.00 & 1.00 & 0.13 & 0.18 & $0.00 * * *$ & \\
\hline GDP growth & 2.96 & 1.52 & -2.78 & 4.69 & 2.96 & 2.99 & 0.70 & \\
\hline Total stock traded growth & 0.22 & 0.25 & -0.30 & 0.58 & 0.23 & 0.22 & 0.43 & 1 \\
\hline Value of transaction & 4.78 & 2.23 & -2.30 & 11.40 & 5.50 & 4.41 & $0.00 * * *$ & \\
\hline Ownership percentage & 0.64 & 0.44 & 0.00 & 1.00 & 0.69 & 0.75 & $0.00 * * *$ & \\
\hline Acquirer size & 7.18 & 2.11 & 1.36 & 13.40 & 7.75 & 6.77 & $0.00 * * *$ & \\
\hline Acquirer cash flow & 0.08 & 0.10 & 0.00 & 0.86 & 0.07 & 0.11 & $0.00 * * *$ & \\
\hline Acquirer leverage & 0.53 & 0.21 & 0.01 & 1.48 & 0.56 & 0.50 & 0.00 **** & \\
\hline Acquirer Tobin's Q & 2.03 & 1.54 & 0.48 & 20.01 & 2.10 & 2.07 & 0.73 & \\
\hline Accruals quality & 0.05 & 0.05 & 0.00 & 0.38 & 0.01 & 0.08 & $0.00 * * *$ & \\
\hline Size of the target & 5.49 & 1.97 & -1.23 & 12.13 & 6.36 & 4.86 & $0.00 * * *$ & \\
\hline Note: $* * * p<0.05$ & & & & & & & & Descriptive statistics \\
\hline
\end{tabular}

significant for most of the variables, which indicate that the transparent targets are different from the opaque targets in our sample.

We now run the regression for stock performance: the panel regression model is as follows:

$$
C A R_{i t} \text { or } B H A R_{i t}=\alpha+\beta_{1} * t c_{i t}+\beta_{2} * t c_{i t}{ }^{2}+\gamma^{\prime} \text { Control variables } i t+\mu_{i}+\varepsilon_{i t}
$$

where $C A R$ is the cumulative abnormal returns of the acquirer/newly merged firm, BHAR is the buy-and-hold abnormal returns of the acquirer/newly merged firm, $t c$ is the time until deal completion, $t c^{2}$ is the squared term of time until deal completion, $\mu_{i}$ are firm fixed effects and $\varepsilon$ is the error term.

For the purpose of making the tables concise, we do not report all the country- and firmlevel and deal-specific control variables howbeit they are included in all regressions we run. Table 2 presents the results for the regressions in equation (15) below.

When we run the regressions for the whole sample with respect to stock performance, we find an inverse U-shaped relationship between post-merger performance and time until deal completion in the short horizon of three months. When we divide the sample into the high information asymmetry group and the low information asymmetry group, we find support for both $\mathrm{H1}$ and H2. Though not significant in the short horizon, we find an inverse U-shaped relationship in the long horizon for the deals involving opaque targets. This supports $H 1$. The inverse U-shaped relationship in this group persists for the long term while it is non-existent for the transparent group, providing support for $\mathrm{H} 2$.

We have argued that, if the projections of the investor in the model we presented, which underlie the due diligence hypothesis and the overdue hypothesis are correct, then this should also reflect in the acquirer's financial performance post-deal. We test this assertion empirically in the discussion that follows. The panel regression model we run is shown in equation (16) below:

$$
\Delta R O A_{i t}=\alpha+\beta_{1} * t c_{i t}+\beta_{2} * t c_{i t}^{2}+\gamma^{\prime} \text { Control variables } i t+\mu_{i}+\varepsilon_{i t}
$$


Time until completion

Time until completion squared
Control variables and fixed effect

Optimum time until completion(days)

U-test ( $p$-value)

U-test-implication

Observations

$R^{2}$

Number of firms

Time until completion

Time until completion squared

Control variables and fixed effect

Optimum time until completion (days)

U-test ( $p$-value)

U-test-implication

Observations

$R^{2}$

Number of firms

Time until completion

Time until completion squared

Control variables and fixed effect

Optimum time until completion (days)

U-test ( $p$-value)

U-test-implication

Observations

$R^{2}$

Number of firms

$0.002900 *$ *
$-0.000028^{*} * *$
$\mathrm{Y}$
52
0.02

Strong inverse U 1,499

0.112

979

0.002322
-0.000100
$\mathrm{Y}$
12
0.35
Monotone/U
623
0.226
498

0.002919
$-0.000033^{* * *}$
$\mathrm{Y}$
44
0.07
Weak inverse U
561
0.165
426

Whole sample 0.001223 $-0.000018$ $\mathrm{Y}$ 34 0.37

Monotone/U 1,494 0.076

974

Opaque targets 0.047026 ****
$-0.001469 * * * *$ $\mathrm{Y}$ 16 0.00

Strong inverse U 622

0.307 497

0.007954 $-0.000076$ $\mathrm{Y}$ 52 0.09

Weak inverse U 1,478 0.072 959

\section{Transparent targets}

$-0.000361$

$-0.000015$

$\mathrm{Y}$

$-12$

Monotone/U 559 0.155 424

\section{$0.050680 * *$ $-0.001605^{* * *}$ $\mathrm{Y}$ 16 0.02}

Strong inverse U 615

0.346 490

0.003738 $-0.000045$

Y

42

0.24

Monotone/U 556 0.062 421
Table 2.

Effect of time until completion on stock performance using accruals quality of target to proxy for information asymmetry
Notes: Regressing our performance measure (CAR/BHAR) on time until deal completion and its squared term for different periods post-merger, the table is a combined test of the due diligence hypothesis and the overdue hypothesis. To test the role played by information asymmetry of the target, the sample is partitioned into opaque and transparent targets using the accrual quality of the target as a proxy for information asymmetry. Control variables include the national- and firm-level and deal-specific variables as explained in the Appendix. Firm fixed effect is included in all models and the optimum time until deal completion and the results of the stringent test of quadratic relation, following Lind and Mehlum (2010) are also reported. Standard errors are corrected for heteroscedasticity and clustered at the firm level. $* * * p<$ $0.01, * * p<0.05 ; * p<0.1$

where $R O A$ is the earnings before interest, taxes, depreciation and amortization (EBITDA) scaled by total assets of the acquirer/newly merged firm after $t$-years, $t c$ is the time until deal completion, $t c^{2}$ is the squared term of time until deal completion, $\mu_{i}$ are firm fixed effects and $\varepsilon$ is the error term.

Our results in Table 3 show a similar pattern as the results in Table 2 supporting all two hypotheses. Particularly, it can be observed that the results for transparent targets show that the inverse U-shaped relationship does not hold in any of the time horizons confirming $H 1$ and H2. Only the results relating to opaque targets are significant and for the long horizon providing evidence in support of $H 2$. 
(1)

\begin{tabular}{l}
$\triangle R O A$ \\
\hline Time until completion \\
Time until completion squared \\
Control variables and fixed effect \\
Optimum time until completion (days) \\
U-test ( $p$-value) \\
U-test-implication \\
Observations \\
$R^{2}$
\end{tabular}

Number of firms

Time until completion

Time until completion squared

Control variables and fixed effect

Optimum time until completion (days)

U-test ( $p$-value)

U-test-implication

Observations

$R^{2}$

Number of firms

Time until completion

Time until completion squared

Control variables and fixed effect

Optimum time until completion (days)

U-test ( $p$-value)

U-test-implication

Observations

$R^{2}$

Number of firms

(2)

Two years

(3)

Five years

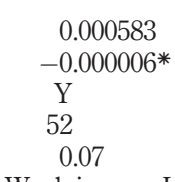

Weak inverse U

1,392

0.116

900

0.001295

$-0.000042$

$\mathrm{Y}$

16

0.3

Monotone/U

580

0.125

462

0.000828
-0.000007
Y
63
0.15
Monotone/U
522
0.339
397

Whole sample

$0.001468^{* * * *}$
$-0.000015^{* * * *}$

$\mathrm{Y}$

50

0.00

Strong inverse U

1,309

0.135

832

Opaque targets

0.003473

$-0.000063$

$\mathrm{Y}$

28

0.18

Monotone/U

540

0.117

427

Transparent targets

0.001069

$-0.000011^{*}$

Y

47

0.11

Monotone/U

495

0.300

372
0.000487

$-0.000006$

$\mathrm{Y}$

38

0.25

Monotone/U

1,047

0.181

659

$0.008499 * *$

-0.000356 ***

$\mathrm{Y}$

12

0.02

Strong inverse U

434

0.291

338

0.000757

$-0.000008$

$\mathrm{Y}$

46

0.24

Monotone/U

389

0.570

294

Notes: Regressing our performance measure (change in return on assets) on time until deal completion and its squared term for different periods post-merger, the table is a combined test of the due diligence hypothesis and the overdue hypothesis. To test the role played by information asymmetry of the target, the sample is partitioned into opaque and transparent targets using the accrual quality of the target as a proxy for information asymmetry. Control variables include the national- and firm-level and deal-specific variables as explained in the appendix. Firm fixed effect is included in all models and the optimum time until deal completion and the results of the stringent test of quadratic relation, following Lind and Mehlum (2010) are also reported. Standard errors are corrected for heteroscedasticity and clustered at the firm level. **** $p<0.01, * *{ }^{*} p<0.05 ; *$ * $p<0.1$

Table 3.

Effect of time until completion on

financial

performance using accruals quality of target to proxy for information asymmetry

\subsection{Robustness checks}

Despite dividing our sample into sub-samples, which could result in a loss of power, we still find significant results for the long horizon for the opaque targets so we believe the case has been made for the hypotheses we test. However, for robustness, we re-run all our regressions using other proxies for information asymmetry: the size of the target firm and Tobin's Q of the target firm. By using this measure, we observe qualitatively similar results as above. The results using size of the target are in Tables 4 and 5 below.

As can be observed from Tables 4 and 5, all of $H 1$ and $H 2$ are strongly supported. Both in the short term and the long term, when deals involve an opaque target, the post-merger 
Time until completion

Time until completion squared

134
Control variables and fixed effect

Optimum time until completion (days)

U-test ( $p$-value)

U-test-implication

Observations

$R^{2}$

Number of firms

Time until completion

Time until completion squared

Control variables and fixed effect

Optimum time until completion (days)

U-test ( $p$-value)

U-test-implication

Observations

$R^{2}$

Number of firms

Time until completion

Time until completion squared

Control variables and fixed effect

Optimum time until completion (days)

U-test ( $p$-value)

U-test-implication

Observations

$R^{2}$

Table 4.

Robustness checkeffect of time until completion on stock performance using size of target to proxy for information asymmetry

$0.002819 * *$
$-0.000019 *$
Y
73
0.06

Weak inverse U 1,933

1,234

0.113
$0.005487 * * * *$
$-0.000045 * * *$
$\mathrm{Y}$
61
0.00

Strong inverse U

541

0.096

379

-0.008052
$0.000211^{*}$
$Y$
19
0.13
Monotone/U
788
0.176
611

\begin{tabular}{c} 
Whole sample \\
\hline 0.000319 \\
0.000006 \\
Y \\
-26
\end{tabular}

Monotone/U

1,927

0.075

1,229
Opaque targets
$0.008525^{*} *$
$-0.000075 * * *$
Y
57

0.00

Strong inverse $\mathrm{U}$

540

0.145

378

Transparent targets

$-0.013653$

0.000285

$\mathrm{Y}$

24

0.25

Monotone/U

784

0.080

607

$$
\begin{gathered}
0.002588 \\
0.000004 \\
\mathrm{Y} \\
-302 \\
- \\
\text { Monotone/U } \\
1,905 \\
0.074 \\
1,210 \\
\\
0.009314 \\
-0.000084 \\
\mathrm{Y} \\
55 \\
0.11 \\
\text { Monotone/U } \\
538 \\
0.104 \\
376
\end{gathered}
$$

$-0.000808$

0.000044

$\mathrm{Y}$

9

0.49

Monotone/U

770

0.108

594

Notes: Regressing our performance measure (CAR/BHAR) on time until deal completion and its squared term for different periods post-merger, the table is a combined test of the due diligence hypothesis and the overdue hypothesis. To test the role played by information asymmetry of the target, the sample is partitioned into opaque and transparent targets using the size of the target as a proxy for information asymmetry. Control variables include the national- and firm-level and deal-specific variables as explained in the appendix. Firm fixed effect is included in all models and the optimum time until deal completion and the results of the stringent test of quadratic relation, following Lind and Mehlum (2010) are also reported. Standard errors are corrected for heteroscedasticity and clustered at the firm level. $* * * x<0.01$, ** $p<0.05 * 0<0.1$

performance-time until deal completion nexus is stronger while this effect is non-existent or very weak when deals involve a transparent target in line with our expectations. Simply put, opaque targets drive the effect documented in Thompson and Kim (2020). Further, this effect dissipates over time so that the effect is stronger in the short term than in the long term. The results using Tobin's Q of the target are in Tables 6 and 7 below:

When we use Tobin's $\mathrm{Q}$ of the target as a proxy for information asymmetry and compare between opaque targets and transparent targets, we observe significant results, albeit weak, for only the sample involving opaque targets and only for the period 2 years after the close of the deal. The test of U-shaped relationship does not support the existence of an inverse U-shaped relationship in any of the regressions but as we find some significant results on the squared term of time until deal completion with respect to 
(1)

$\triangle R O A$

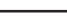

Time until completion

Time until completion squared

Control variables and fixed effect

Optimum time until completion (days)

U-test ( $p$-value)

U-test-implication

Observations

$R^{2}$

Number of firms

Time until completion

Time until completion squared

Control variables and fixed effect

Optimum time until completion (days)

U-test ( $p$-value)

U-test-implication

Observations

$R^{2}$

Number of firms

Time until completion

Time until completion squared

Control variables and fixed effect

Optimum time until completion (days)

U-test ( $p$-value)

U-test-implication

Observations

$R^{2}$

Number of firms

0.3

1,723

0.105

1,087 471

0.125

333
(2)

Two years

(3)

Five years

Whole sample

$-0.000008$

$\mathrm{Y}$

68

0.09

Monotone/U

$0.001174 * *$
$-0.000009 *$
$Y$
63
0.03

Strong inverse U

-0.002816
0.000049
$Y$
29
0.15
Monotone/U
714
0.124
545

Weak inverse $\mathrm{U}$ 1,626

0.127

1,007

$0.001894^{* * * *}$

$-0.000017 * * *$

$\mathrm{Y}$

57

0.00

Strong inverse $\mathrm{U}$

452

0.137

312

Transparent targets

$-0.001342$

0.000023

$\mathrm{Y}$

29

0.35

Monotone/U

663

0.136

501
Opaque targets
0.000221

$-0.000001$

$\mathrm{Y}$

104

Monotone/U

1,277

0.167

785

0.000518

$-0.000004$

$\mathrm{Y}$

58

0.29

Monotone/U

357

0.205

257

0.004104

$-0.000073$

$\mathrm{Y}$

28

0.06

Weak inverse U

519

0.336

385

Notes: Regressing our performance measure (change in return on assets) on time until deal completion and its squared term for different periods post-merger, the table is a combined test of the due diligence hypothesis and the overdue hypothesis. To test the role played by information asymmetry of the target, the sample is partitioned into opaque and transparent targets using the size of the target as a proxy for information asymmetry. Control variables include the national- and firm-level and deal-specific variables as explained in the appendix. Firm fixed effect is included in all models and the optimum time until deal completion and the results of the stringent test of quadratic relation, following Lind and Mehlum (2010) are also reported. Standard errors are corrected for heteroscedasticity and clustered at the firm level. $* * * p<$ $0.01, * * p<0.05 ; * p<0.1$

Post-M\&A performance

135

Table 5.

Robustness checkeffect of time until completion on financial performance using size of target to proxy for information asymmetry

opaque targets while none of the results are significant for transparent targets, the results are qualitatively similar to the findings of the main regressions and in the spirit of the discussions so far.

\section{Conclusion}

In this study, we have developed and presented a simple theoretical model to explain the due diligence hypothesis and the overdue hypothesis found in Thompson and Kim (2020). Our model hinges on a market with three players, namely, the acquirer, target and the investor. In the bid of the acquirer to buy the target, the acquirer undertakes due diligence to satisfy itself of the quality of the deal, which involves the incurring of direct costs in terms of 
Time until completion

Time until completion squared
Control variables and fixed effect

Optimum time until completion (days)

U-test ( $p$-value)

U-test-implication

Observations

$R^{2}$

Number of firms

Time until completion

Time until completion squared

Control variables and fixed effect

Optimum time until completion (days)

U-test ( $p$-value)

U-test-implication

Observations

$R^{2}$

Number of firms

Time until completion

Time until completion squared

Control variables and fixed effect

Optimum time until completion (days)

U-test ( $p$-value)

U-test-implication

Observations

$R^{2}$

Table 6.

Number of firms

0.004153
-0.000044
$\mathrm{Y}$
42,745
-
Monotone/U
806
0.072
644

$0.008008^{*}$

$-0.000123$

$\mathrm{Y}$

29,348
Monotone/U
397
0.210
327

-0.005631
0.000094
$\mathrm{Y}$
26,825
-
Monotone/U
409
0.312
352

$$
\begin{gathered}
\text { Whole sample } \\
\hline 0.005862 \\
-0.000060 \\
\text { Y } \\
44,240
\end{gathered}
$$

Monotone/U

804

0.148

642

Opaque targets

0.013893

$-0.000235$

$\mathrm{Y}$

26,578

Monotone/U
397

0.353

327

Transparent targets

$-0.010377$

0.000121

$\mathrm{Y}$

38,745

Monotone/U
407

0.153

350
0.016658

$-0.000235$

$\mathrm{Y}$

31,860

Monotone/U

794

0.115

632

$0.042730 *$

$-0.000806 *$

$\mathrm{Y}$

23,859
Monotone/U
394
0.333
324

$-0.013403$

0.000103

$\mathrm{Y}$

58,341

Monotone/U

400

0.224

343
Robustness checkeffect of time until completion on stock performance using Tobin's Q of target to proxy for information asymmetry
Notes: Regressing our performance measure (CAR/BHAR) on time until deal completion and its squared term for different periods post-merger, the table is a combined test of the due diligence hypothesis and the overdue hypothesis. To test the role played by information asymmetry of the target, the sample is partitioned into opaque and transparent targets using Tobin's $\mathrm{Q}$ of the target as a proxy for information asymmetry. Control variables include the national-and firm-level and deal-specific variables as explained in the appendix. Firm fixed effect is included in all models and the optimum time until deal completion and the results of the stringent test of quadratic relation, following Lind and Mehlum (2010) are also reported. Standard errors are corrected for heteroscedasticity and clustered at the firm level. $* * * p<0.01,{ }^{*} p<<0.05$ and ${ }^{*} p<0.1$

resources and indirectly in terms of time. While the benefits of synergy expected to result from the deal are time-bound and delays could result in the loss of these synergies, the acquirer desires to quickly close the deal and at the same time has to perform adequate due diligence. The investor, not being a direct party to the closed-door negotiations between the acquirer and the target, takes the time until deal completion as the main signal to update his information set concerning the ex-ante probability that the acquirer/newly merged firm will experience superior or poor performance post-merger. Our model projects that the relationship documented by Thompson and Kim (2020) is stronger when the deal includes opaque targets suggesting that information asymmetry plays a vital role in the post-M\&A performance-time until deal completion nexus. 
(1)

$\triangle R O A$

Time until completion

Time until completion squared

Control variables and fixed effect

Optimum time until completion (days)

U-test ( $p$-value)

U-test-implication

Observations

$R^{2}$

Number of firms

Time until completion

Time until completion squared

Control variables and fixed effect

Optimum time until completion (days)

U-test ( $p$-value)

U-test-implication

Observations

$R^{2}$

Number of firms

Time until completion

Time until completion squared

Control variables and fixed effect

Optimum time until completion (days)

U-test ( $p$-value)

U-test-implication

Observations

$R^{2}$

Number of firms

717

568

23,711$$
\begin{array}{r}
\mathrm{Y} \\
13,579
\end{array}
$$

(2)

Two years

(3)

Five years

One year

0.001133
-0.000016
$\mathrm{Y}$
32,072

Monotone/U

0.167

$$
\begin{array}{r}
0.002430 \\
-0.000046 \\
\mathrm{Y}
\end{array}
$$

-
Monotone/U
366
0.173
299

$$
\begin{array}{r}
-0.000504 \\
0.000017
\end{array}
$$$$
\begin{gathered}
- \\
\text { Monotone/U } \\
351 \\
0.429 \\
299
\end{gathered}
$$

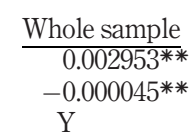

29,619

$$
\text { Monotone/U }
$$

0.251

528

Opaque targets

$0.005606^{* * *}$

$-0.000103^{*}$

$\mathrm{Y}$

24,375

Monotone/U

345

0.209

282

Transparent targets

$-0.000455$

0.000014

$\mathrm{Y}$

14,547

Monotone/U

327

0.425

276
$-0.000044$

23,948

Monotone/U

504

0.318

392

0.004836

$-0.000078$

27,992

Monotone/U

262

0.353

214

0.000100

0.000008

$\mathrm{Y}$

$-5,748$

Monotone/U

242

0.416

204
Post-M\&A performance

137

Notes: Regressing our performance measure (change in return on assets) on time until deal completion and its squared term for different periods post-merger, the table is a combined test of the due diligence hypothesis and the overdue hypothesis. To test the role played by information asymmetry of the target, the sample is partitioned into opaque and transparent targets using Tobin's Q of the target as a proxy for information asymmetry. Control variables include the national- and firm-level and deal-specific variables as explained in the appendix. Firm fixed effect is included in all models and the optimum time until deal completion and the results of the stringent test of quadratic relation, following Lind and Mehlum (2010) are also reported. Standard errors are corrected for heteroscedasticity and clustered at the firm level. $* * * p<$ $0.01, * * p<0.05 * p<0.1$

Table 7.

Robustness checkeffect of time until completion on

financial

performance using Tobin's Q of target to proxy for information asymmetry

We find that mergers that involve more opaque firms as targets, which take a shorter time to close perform better, while those that take too long to close experience poor post-M\&A performance. Conversely, the effect is very weak or completely non-existent when the targets are transparent. These results hold for the short term supporting the evidence that information asymmetry problems are severe before the merger is consummated and become attenuated post-merger.

In conclusion, dealing with a target one does not know well about and does not properly investigate could spell doom for an acquirer but it is important to be timely in making decisions because a good decision timed wrongly remains a poor decision made. 
1. $E\left(p_{n, t_{c}} \mid I_{n, t_{c}}\right)=E\left(p_{n, t} \mid I_{n, t}\right)+E\left(z_{n}\right)-E\left(c_{n}\right)=E\left(f_{n, t} \mid I_{n, t}\right)+E\left(z_{n}\right)-E\left(c_{n}\right)=E\left(f_{n, t}+z_{n}-c_{n} \mid I_{n, t}\right)$

2. It is known that acquirers have incentive to still see a deal through despite delays because of exorbitant break-up fees (Boeh, 2011; Butler and Sauska, 2014).

\section{8}

\section{References}

Akerlof, G.A. (1970), "The market for lemons: Quality uncertainty and the market mechanism”, The Quarterly Journal of Economics, Vol. 84 No. 3, pp. 488-500.

Armstrong, C.S., Core, J.E., Taylor, D.J. and Verrecchia, R.E. (2011), "When does information asymmetry affect the cost of capital?", Journal of Accounting Research, Vol. 49 No. 1, pp. 1-40.

Bartov, E. and Bodnar, G.M. (1996), "Alternative accounting methods, information asymmetry and liquidity: theory and evidence", Accounting Review, pp. 397-418.

Bhagwat, V., Dam, R. and Harford, J. (2016), “The real effects of uncertainty on merger activity”, Review of Financial Studies, Vol. 29 No. 11, pp. 3000-3034.

Boeh, K.K. (2011), "Contracting costs and information asymmetry reduction in cross-border M\&A", Journal of Management Studies, Vol. 48 No. 3, pp. 568-590.

Butler, F.C. and Sauska, P. (2014), "Mergers and acquisitions: termination fees and acquisition deal completion", J. Manag. Issues, Vol. 26, pp. 44-54.

Caiazza, S. and Pozzolo, A. (2016), "The determinants of failed takeovers in the banking sector: deal or country characteristics?”, Journal of Banking and Finance, Vol. 72, pp. S92-S103.

Coase, R.H. (1937), “The nature of the firm”, Economica, Vol. 4 No. 16, pp. 386-405.

Core, J.E., Guay, W.R. and Verdi, R. (2008), "Is accruals quality a priced risk factor?", Journal of Accounting and Economics, Vol. 46 No. 1, pp. 2-22.

Cramton, P.C. (1991), "Dynamic bargaining with transaction costs", Management Science, Vol. 37 No. 10, pp. 1221-1233.

Dechow, P.M. and Dichev, I. (2002), "The quality of accruals and earnings: the role of accrual estimation errors", The Accounting Review, Vol. 77 No. s-1, pp. 35-59.

Demidova, I. (2014), “Time lost in negotiations: productive or wasteful?”, Available at SSRN 2364718.

Easterwood, C.M. (1998), "Takeovers and incentives for earnings management: an empirical analysis”, Journal of Applied Business Research (Jabr)), Vol. 14 No. 1, pp. 29-48.

Ferreira, M.P., Borini, F., Vicente, S. and Almeida, M.R. (2017), "The pre-acquisition process: the temporal hiatus between the announcement and completion in foreign acquisitions in Brazil", International Journal of Emerging Markets, Vol. 12 No. 2, pp. 400-414.

Francis, J., LaFond, R., Olsson, P. and Schipper, K. (2005), "The market pricing of accruals quality", Journal of Accounting and Economics, Vol. 39 No. 2, pp. 295-327.

Fuller, K.P. (2003), "Why some firms use collar offers in mergers", The Financial Review, Vol. 38 No. 1, pp. $127-150$.

Goktan, M.S. (2013), How Does Information Asymmetry Affect the Division of Gains in Mergers?, Managerial Finance.

Hansen, R.G. (1987), “A theory for the choice of exchange medium in mergers and acquisitions”, The Journal of Business, Vol. 60 No. 1, pp. 75-95.

Howe, J.S. and and Morillon, T.G. (2017), "Do mergers and acquisitions affect information asymmetry in the banking sector?", Networks Financial Institute working paper series.

Hwang, J.E. and Roh, T. (2015), "Successful M\&A experiences: breadth, depth, and deal duration in the US semiconductor industry", In Academy of Management Proceedings; Academy of Management: Briarcli Manor, New York, NY, 10522. 
Kesner, I.F., Shapiro, D.L. and Sharma, A. (1994), "Brokering mergers: an agency theory perspective on the role of representatives", Academy of Management Journal, Vol. 37 No. 3, pp. 703-721.

Kim, D. and Qi, Y. (2010), "Accruals quality, stock returns, and macroeconomic conditions", The Accounting Review, Vol. 85 No. 3, pp. 937-978.

Lambert, R.A., Leuz, C. and Verrecchia, R.E. (2012), "Information asymmetry, information precision, and the cost of capital", Review of Finance, Vol. 16 No. 1, pp. 1-29.

Lee, G. and Masulis, R.W. (2009), "Seasoned equity offerings: quality of accounting information and expected flotation costs", Journal of Financial Economics, Vol. 92 No. 3, pp. 443-469.

Lind, J.T. and Mehlum, H. (2010), "With or without U? The appropriate test for a U-shaped relationship", Oxford Bulletin of Economics and Statistics, Vol. 72 No. 1, pp. 109-118.

Louis, H. and Sun, A.X. (2016), "Abnormal accruals and managerial intent: evidence from the timing of merger announcements and completions", Contemporary Accounting Research, Vol. 33 No. 3, pp. 1101-1135.

Luypaert, M. and Caneghem, V.T. (2014), "Can auditors mitigate information asymmetry in M\&As? An empirical analysis of the method of payment in Belgian transactions", Auditing: A Journal of Practice and Theory, Vol. 33 No. 1, pp. 57-91.

Luypaert, M. and De Maeseneire, W. (2015), "Antecedents of time to completion in mergers and acquisitions", Applied Economics Letters, Vol. 22 No. 4, pp. 299-304.

Picquet, T. (2017), "Determinants of deal duration in mergers and acquisitions: are they the same for private and public targets? Louvain school of management, université catholique de louvain. Prom.:béreau, sophie", available at: http://hdl.handle.net/2078.1/thesis:11147

Reuer, J. and Shen, J.C. (2004), "Sequential divestiture through initial public offerings", Journal of Economic Behavior and Organization, Vol. 54 No. 2, pp. 249-266.

Spence, A.M. (1974), Market signaling: Informational Transfer in Hiring and Related Screening Processes, Harvard University Press, Cambridge, MA.

Thompson, E.K. and Kim, C. (2020), "Post-M\&A performance and failure: implications of time until deal completion", Sustainability, Vol. 12 No. 7, p. 2999.

Wangerin, D. (2019), "M\&A due diligence, post-acquisition performance, and financial reporting for business combinations", Contemporary Accounting Research, Vol. 36 No. 4, pp. 2344-2378.

Williamson, O.E. (1975), Markets and Hierarchies, Analysis and Antitrust Implications: A Study in the Economics of Internal Organization, Free Press, New York, NY.

Yu, M. (2012), "Essays on information asymmetry and the firm”, Unpublished doctoral dissertation. University of Iowa. 
Dependent variables

CAR and BHAR

140

\section{ROA}

Information asymmetry: partitioning variables Accruals quality

Size of the target Target Tobin's Q

\section{Independent variable} Time until completion

Control variables

Cash payment

Industry difference

GDP growth

Total stock traded growth

Value of transaction

Ownership percentage

Acquirer size Acquirer cash flow

Table A1.

Definition of Acquirer leverage Acquirer Tobin's Q
Definition of variables

The cumulative abnormal returns and the buy and hold abnormal returns of the acquirer or newly merged firm after the deal

The earnings before interest, taxes, depreciation and amortization (EBITDA) divided by total assets

Accruals quality calculated following Dechow and Dichev (2002), Kim and Qi (2010)

The log of total assets of the target firm

Tobin's Q of the target firm. Tobin's Q is defined as the ratio of total assets plus market capitalization minus common equity minus deferred taxes and investment tax credit to total assets

The time difference between the announcement and effective date of the deal in months

A dummy variable equal to one if the deal is financed by all or majority cash and zero otherwise

A dummy variable that equals one if the acquirer and target firms belong to different industries, and zero otherwise

The annual GDP growth rate of the target countries

The calculated annual growth of the total stock market value of the target countries

The log of the total value of the consideration paid by the acquirer, excluding fees and expenses

The percentage ownership of the acquirer after the deal

The log of total assets of the acquirer firm

The cash flow of the acquirer firm divided by its total assets

The total liabilities of the acquirer firm divided by its total assets

The Tobin's Q of the acquirer firm. Tobin's Q is defined as the ratio of total assets plus market capitalization minus common equity minus deferred taxes and investment tax credit to total assets

\section{Corresponding author}

Changki Kim can be contacted at: changki@korea.ac.kr

For instructions on how to order reprints of this article, please visit our website: 